\title{
PASSIVHAUS APLICADO AO INSTITUTO DE ARTES LYGIA PAPE
}

\author{
PASSIVHAUS APPLIED TO LYGIA PAPE ARTS INSTITUTE
}

\section{Thaís Fernandes Vilela; \\ Aline Silva Sauer; Sandra L. Moscon Coutinho.}

\author{
Palavras Chave \\ Passivhaus; Arquitetura passiva; Eficiência energética
}

\section{Key Words}

Passivhaus; Passive architecture; Energy efficiency

\section{RESUMO}

Atualmente as crescentes demandas por energia configuram-se em um dos maiores problemas da construção civil, visto que a maior parcela do gasto energético parte justamente do uso e manutenção das edificações. Neste contexto, a Arquitetura Passiva tem sido aplicada no intuito de projetar ambientes termicamente confortáveis com menor gasto energético possível. Assim, esta pesquisa objetiva estudar a aplicação do conceito Passivhaus, e de seus preceitos fundamentais, no projeto arquitetônico do Instituto de Artes Lygia Pape, verificando a adaptação desta norma à zona bioclimática brasileira 8. A norma Passivhaus foi primeiramente empregada nos climas frios do norte da Europa, a partir da década de 1980, e vem sendo ao longo dos anos adaptada para os climas mais quentes. Neste artigo é apresentado o projeto arquitetônico proposto para o Instituto de Artes, junto aos recursos demandados para a melhor apropriação da norma ao clima da região brasileira pertencente a zona bioclimática 8, onde encontra-se a cidade de Vitória-ES. Por fim, os dados relativos ao desempenho térmico do edifício são obtidos através da ferramenta Passive House Planning Package (PHPP), esses resultados são confrontados com a referida norma e com a norma de desempenho térmico brasileira NBR 15220:2005. Como resultado observa-se a viabilidade de aplicação da norma alemã, com adequações as peculiaridades climáticas, a edificações localizadas na zona bioclimática brasileira 8 . Além disso, ressalta-se que a aplicação dos princípios fundamentais desta norma em edificações brasileiras indica uma redução do gasto energético durante a fase de uso e manutenção da edificação.

\section{ABSTRACT}

VNowadays, the growing demands for energy are one of the biggest problems of civil construction, since most of the energy expenditure is due to the use and maintenance of buildings. In this context, Passive Architecture has been applied in order to design thermally comfortable environments with the lowest possible energy expenditure. Thus, this research aims to study the application of the Passivhaus concept and its fundamental precepts in the architectural project of the Lygia Pape Institute of Arts, verifying the adaptation of this standard to the Brazilian bioclimatic zone 8. The Passivhaus standard was first used in northern cold climates Of Europe, from the 1980s, and has been over the years adapted to the warmer climates. This article presents the proposed architectural project for the Institute of Arts, together with the resources required for the best appropriation of the norm for the climate of the Brazilian region belonging to the bioclimatic zone 8, where the city of Vitória-ES is located. Finally, the data on the thermal performance of the building are obtained through the tool Passive House Planning Package (PHPP), these results are compared with the referred standard and the Brazilian thermal performance norm NBR 15220: 2005. As a result, it is possible to observe the feasibility of applying the German standard, with adaptations to climatic peculiarities, to buildings located in the Brazilian bioclimatic zone. In addition, it is emphasized that the application of the fundamental principles of this standard in Brazilian buildings indicates a reduction of the expenditure During the use and maintenance phase of the building. 


\section{INTRODUÇÃO}

O crescimento progressivo do consumo de energia, junto à exaustão das reservas naturais e ao crescimento descontrolado das cidades, acarretou em várias discussões por uma arquitetura mais sustentável, no sentido de suprimento do próprio consumo energético. Deste modo, normas, leis e certificações surgiram para atender a essa necessidade. A união dos conceitos passivos às tecnologias advindas do desenvolvimento dos materiais e sistemas construtivos tornou possível aplicação da norma Passivhaus aos climas menos amenos (WASSOUF, 2014).

A Arquitetura Passiva possibilita o conforto térmico através de técnicas que permitem melhores condições de ventilação e iluminação com menor demanda de energia elétrica. O conceito Passivhaus vem agregar ao design passivo, princípios capazes de reduzir os gastos energéticos e as emissões de dióxido de carbono, por meio de soluções práticas apropriadas para serem adaptadas às condicionantes locais e especificidades do projeto (GURGEL, 2012).

Ao contrário da maioria das certificações ambientais, os fundamentos da Passivhaus são flexíveis, com métodos de quantificação da eficiência energética concretos e diretos, que se baseiam em medidas eficazes, as quais vão além do simples controle da energia elétrica, proposto na maioria das normas de desempenho brasileiras (DALBEN, FREITAS, CUNHA, 2015).

$O$ trabalho final de curso, que deu origem ao presente artigo, teve como propósito verificar a aplicabilidade da Arquitetura Passiva, principalmente no que se refere aos conceitos metodológicos da Passivhaus adaptados ao clima da Região metropolitana da Grande Vitória no Estado do Espírito Santo. Analisando, sobretudo, o implemento das técnicas de isolamento térmico, ventilação associada a liberação de calor e conservação de temperatura ambiente adequada às atividades, assim como outros métodos acessíveis que permitam o equilíbrio energético e ambiental da edificação.

\subsection{Objetivo}

O objetivo deste artigo é estudar a aplicação do conceito Passivhaus, e de seus preceitos fundamentais, no projeto arquitetônico do Instituto de Artes Lygia Pape, verificando a adaptação dos princípios norteadores da respectiva norma à zona bioclimática brasileira 8 , onde se insere a cidade de Vitória, capital do Espirito Santo.

\subsection{Metodologia}

A pesquisa apresentada neste artigo divide-se em quatro etapas principais: a primeira apresenta uma revisão bibliográfica sobre tema Passivhaus, recolhendo em diversos autores o desenvolvimento do conceito, seus requisitos básicos e sua metodologia de aplicação: A segunda etapa desta pesquisa envolve a elaboração do projeto arquitetônico do Instituto de Artes Lygia Pape quanto a adaptação e utilização das técnicas extraídas da norma Passivhaus; A terceira etapa consiste na explanação das soluções técnicas empregadas ao edifício em estudo; Finalmente, a quarta etapa apresenta os métodos de captação dos dados através da ferramenta Passive House Planning Package (Pacote para Projetos Passivos) - PHPP e os resultados obtidos.

\section{REVISÃO BIBLIOGRÁFICA}

É de fundamental importância investigar os conceitos que definem a Passivhaus e seus fundamentos dentro da Arquitetura Passiva. Sendo um conceito estrangeiro, primeiramente é necessário compreender seu significado no contexto europeu, para posteriormente analisar seus desdobramentos na adaptação aos climas quentes e sua propagação em diferentes meios.

O conceito Passivhaus desenvolveu-se junto aos conceitos de casa passiva, o próprio termo traz essa significação, Passiv: Passivo, Haus: Casa. A Passivhaus fundamenta-se na Arquitetura Passiva, e utiliza dela para atingir os critérios a que se propõe: gasto mínimo de energia e máximo conforto térmico do usuário. Para a Passivhaus a metodologia do design passivo é o primeiro passo para a elaboração de edifícios eficientes, em que a concepção do projeto parte primeiramente das condicionantes climáticas, físicas e ambientais do local onde a edificação será inserida (GURGEL, 2012).

A Passivhaus além de empregar as condutas da Arquitetura Passiva, busca ainda a eficiência energética, a fim de reduzir ao mínimo as demandas por energia de uma edificação. Dentre os princípios fundamentais do design passivo, que também são utilizados pela Passivhaus, pode-se verificar a adaptação da edificação ao clima local, a correta orientação da construção, aberturas bem posicionadas e protegidas, aproveitamento das massas térmicas, isolamento térmico e ventilação cruzada (GURGEL, 2012).

Os problemas associados às demandas de energia nos países europeus acarretam em grande impacto nos sistemas construtivos, nos hábitos de consumo e até nos modelos culturais da sociedade, tendo em vista que suas fontes energéticas são limitadas. Deste modo, os profissionais de Arquitetura, Engenharia e outras áreas afins da construção civil, assim como a sociedade em geral, estão familiarizados com o modelo de baixa demanda energética. 
No Brasil, o processo de conscientização sobre as questões ambientais, sobretudo acerca da economia de energia, ainda enfrenta resistência, visto que os danos causados pelo enfraquecimento das fontes principais ainda não se manifestaram em sua totalidade. Apesar da visível crise energética junto à crise hídrica, tendo em vista que no país a principal fonte de energia elétrica provém justamente das hidrelétricas, a sociedade ainda encara a redução da demanda apenas como fator econômico, e em segunda estância de preservação ambiental (DALBEN, FREITAS, CUNHA, 2015).

Segundo Costa (2015), a Passivhaus é um conceito construtivo, que define um padrão de qualidade que atenda as demandas por eficiência sobre as questões energéticas, de conforto, e que ainda seja economicamente acessível e ecologicamente correto. Ainda de acordo com esta autora, os edifícios de baixo gasto energético tornaram-se um preceito exigido em vários países europeus, visto que esse tipo de construção emprega uma envoltória térmica de alta qualidade, a prevenção de pontes térmicas, vidros com isolamento e ventilação controlada.

Justamente pela Passivhaus apresentar-se como método construtivo, é possível pensar em sua aplicação em vários contextos, sem desconsiderar as necessidades e peculiaridades do local onde a mesma será inserida. Como seguimento construtivo, o conceito passou por processos que permitiram verificar sua adaptabilidade, primeiramente à pequenas variações climáticas, sociais e culturais, ao partir da Alemanha para o restante do norte europeu, e posteriormente à maiores disparidades ao ser introduzida no sul da Europa (GAVIÃO, 2012).

Deste modo, a partir do modelo de habitação de baixo consumo energético, Wolfgang Feist e Bo Adamson desenvolveram, em 1988, o conceito da casa passiva alemã, construindo o primeiro modelo na cidade de Darmstadt, Alemanha em 1991, o qual é monitorado até hoje, mantendo um elevado nível de eficiência energética e conforto térmico. Assim, para a Passivhaus define-se casa passiva como edificações onde o fluxo mínimo de ventilação para a higienização do ar, impede a perda do calor, e junto às técnicas de ventilação controlada tornam possível a concepção de um edifício de baixo gasto energético e confortável termicamente (WASSOUF, 2014).

Nos países europeus devido aos habituais problemas de produção e captação de energia, conceitos como o Passivhaus, que exigem gasto mínimo da energia, originaram normas e certificações. A Passivhaus como norma de desempenho já é seguida na Alemanha e outros países do norte europeu, como a Áustria. Como modelo de certificação, seu sistema foi disseminado para o sul da Europa e adaptado às diferentes condições climáticas, através do Passivhaus Institut, que surgiu para coordenar o processo de certificação Passivhaus (COSTA, 2015).

A certificação Passivhaus valida os dados através da planilha Passiv house Planning Package (PHPP), além dos dados levantados pela ferramenta, ainda são levados em consideração as soluções utilizadas, e o projeto é analisado por especialistas certificados. A Passivhaus também certifica produtos e sistemas construtivos, deste modo, segundo Gavião (2012), garante a utilização de sistemas testados que obedecem aos padrões da mesma, facilitando a implementação da certificação.

A Passivhaus apresenta determinados procedimentos para certificação, os quais variam de acordo com o uso do edifício, que deve ser certificado em fase de projeto e após a conclusão da obra (COSTA, 2015; GAVIÃO, 2012), recebendo assim o certificado de Quality-Approved Passive House. De acordo com Dalben, Freitas e Cunha (2015), são cinco critérios utilizados para a qualificação dos edifícios:

(1) A carga térmica total do edifício não deve ser superior à $10 \mathrm{~W} / \mathrm{m}^{2}$ e a sua demanda energética para aquecimento interno não pode superar $15 \mathrm{kWh} / \mathrm{m}^{2}$ durante o ano;

(2) A demanda energética para arrefecimento (resfriamento) de toda a edificação não pode ultrapassar $15 \mathrm{kWh} / \mathrm{m}^{2}$ durante o ano;

(3) As demandas de energia primária, ou seja, a energia elétrica gasta com aparelhos eletrodomésticos e afins, não deve superar $120 \mathrm{kWh} / \mathrm{m}^{2}$ durante o ano;

(4) O edifício deve ser hermético apresentando o máximo de 0,60 renovações de ar por hora à pressão de 50 Pascal;

(5) Durante o verão a temperatura nas áreas de maior permanência não deve ser superior a $25^{\circ} \mathrm{C}$ em $10 \%$ das horas durante o ano.

Dentre os critérios exigidos pela Passivhaus, há aqueles normatizados, que compõem o padrão de implementação da certificação e há ainda aqueles que são inerentes ao seu conceito como método originado da Arquitetura Passiva. Segundo Gavião (2012), todos os critérios descritos serão atendidos mediante o emprego de princípios, que em climas quentes são capazes de melhor adaptar a aplicação da norma Passivhaus.

\section{1. Princípios fundamentais da Passivhaus}

A norma Passivhaus possui cinco princípios fundamentais: (1) isolamento térmico da envoltória do edifício; (2) minimização das pontes térmicas; (3) desempenho elevado das esquadrias; (4) estanqueidade do ar e (5) ventilação mecânica com recuperação ou perda de calor 
(DALBEN; FREITAS; CUNHA, 2015). Dentre os critérios oficiais da Passivhaus, no caso do emprego da norma para climas quentes, certos quesitos do conceito podem não ser aplicados, no entanto é necessária sua justificativa mediante cálculos específicos (WASSOUF, 2014).

Quanto à envoltória do edifício, podem-se destacar as vedações opacas e transparentes. Segundo Gavião (2012) é necessário que o isolamento da envolvente opaca do edifício seja capaz de minimizar as perdas térmicas. Atualmente, o mercado dispõe de várias soluções construtivas que podem ser empregadas nesta função, a escolha dependerá principalmente do clima onde será implantada a edificação.

É ideal que o isolamento térmico do edifício seja contínuo, conforme a Figura 1, sobretudo para minimizar as pontes térmicas. As áreas próximas as esquadrias tendem a apresentar menores taxas de isolamento que devem ser compensadas por outras medidas (GAVIÃO 2012; WASSOUF, 2014). Na figura 2 pode-se observar, nos pontos em vermeIho, onde geralmente se formam as pontes térmicas.

Figura 01 - Isolamento térmico contínuo da envoltória.

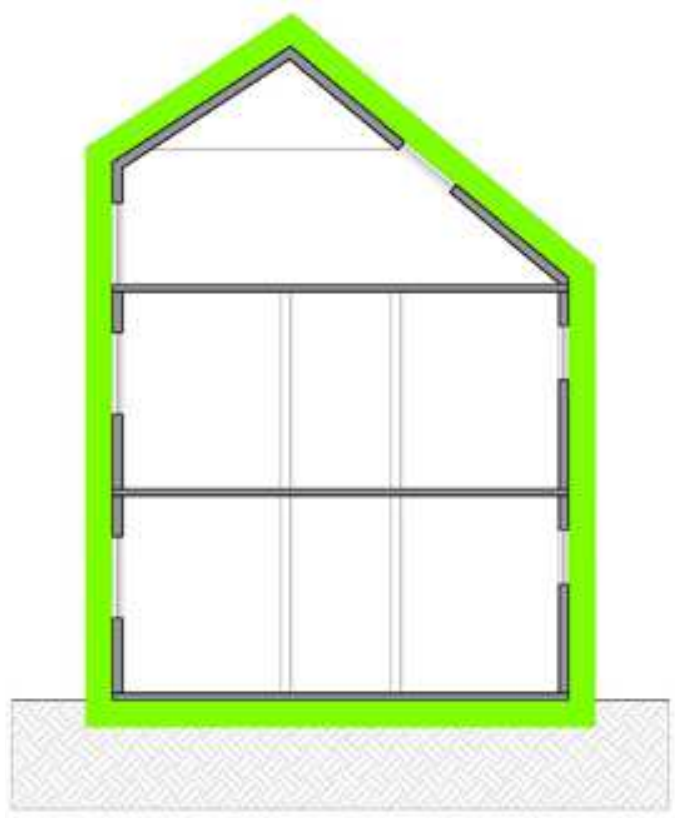

Fonte: adaptado de WASSOUF, 2014.

Costa (2015) define pontes térmicas como áreas da parte externa do edifício que são propícias a perda ou ganho de calor pela diferença das temperaturas entre os ambientes internos e externos. Segundo Wassouf (2014), as pontes térmicas, se não controladas, podem influir diretamente no desempenho energético da edificação.
Figura 02 - Indicação das pontes térmicas na envoltória.

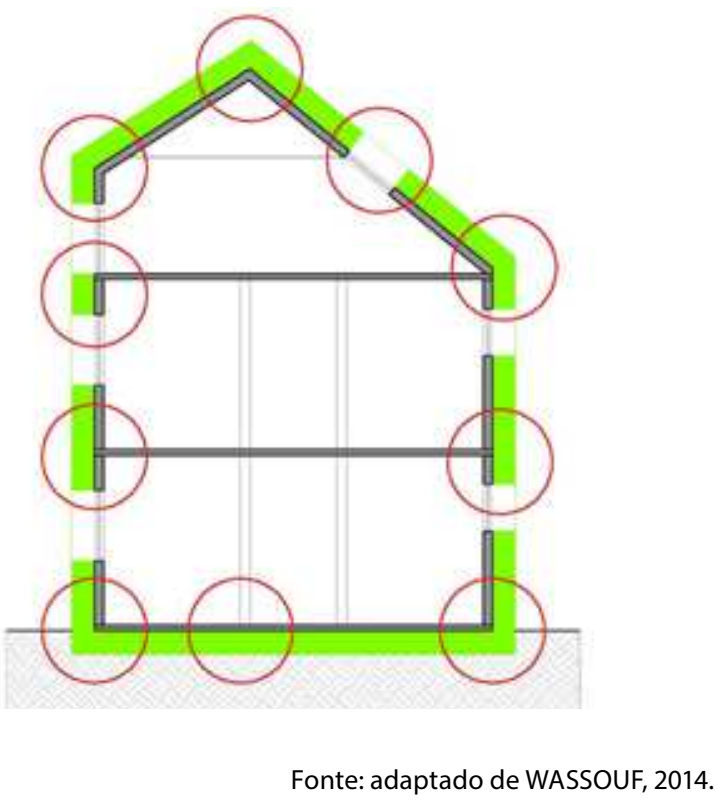

Mesmo que nos climas em que as variações de temperatura interna e externa são mínimas, é indispensável proteger a edificação quanto às perdas ou ganho de calor. As esquadrias são de vital importância para a manutenção da temperatura interior do edifício, ou seja, através das aberturas podem ocorrer passagens do ar gerando perdas ou ganho de calor, além de proporcionar diferenças de temperatura entre a área interna e externa da edificação.

No caso das janelas, através da caixilharia isolante e vidros com baixa emissividade térmica, pode-se manter a temperatura confortável tanto no inverno quanto no verão (COSTA, 2015). Na figura 3, pode-se observar a incidência de radiação nas vedações transparentes, assim é importante posicionar e proteger as aberturas de modo a aproveitar as horas de insolação mais branda no verão, e as mais intensas no inverno, além de captar os ventos predominantes da região.

Figura 03 - Insolação sobre as aberturas no inverno e no verão.

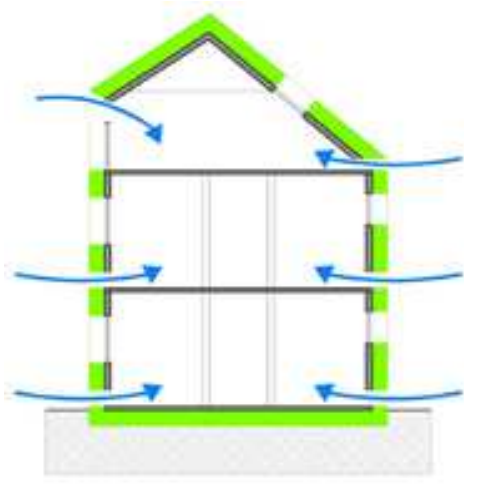

Fonte: adaptado de WASSOUF, 2014 
A estanqueidade é outro fator considerável, entende-se por estanqueidade ao ar a ausência de infiltrações de ar ou o controle da passagem de ar, tendo em vista que devido ao isolamento térmico do edifício, qualquer entrada ou saída de ar pode comprometer a qualidade do conforto ambiental interno, interferindo assim no consumo energético e na proteção acústica (GAVIÃO, 2012; WASSOUF, 2014). As trocas de ar são fundamentais para a saúde do edifício, o controle das infiltrações de ar refere-se às perdas pelas vedações opacas (Figura 4), as aberturas devem garantir a higiene e a renovação do ar constantemente dentro do edifício.

Figura 04 - Infiltração de ar na envoltória

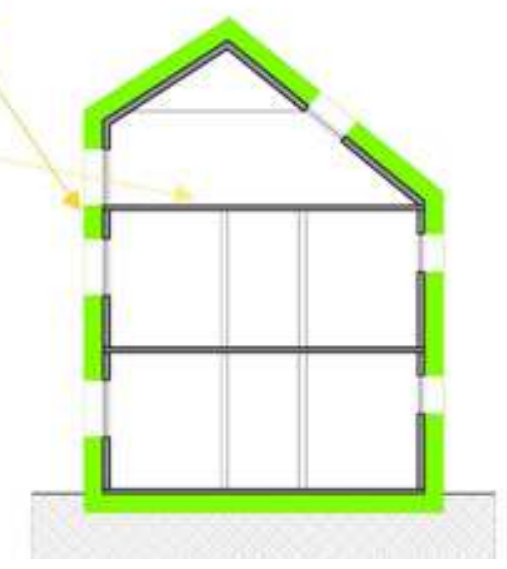

Fonte: adaptado de WASSOUF, 2014.

Segundo Wassouf (2014), a ventilação possibilita a higienização dos ambientes internos garantindo a eliminação dos agentes nocivos à saúde humana, tais como o $\mathrm{CO} 2$, os vapores de água, os compostos orgânicos voláteis e os odores das atividades humanas. Pode-se verificar na figura 5 um esquema de ventilação híbrida, ou seja, a ventilação natural cruzada junto a um sistema de exaustão mecânica.

Figura 05 - Ventilação híbrida.

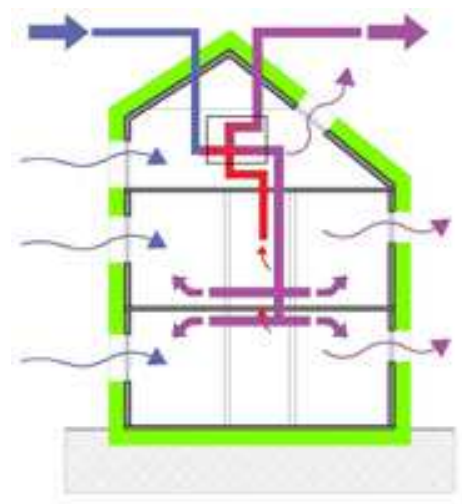

Fonte: adaptado de WASSOUF, 2014.
Desse modo, os cinco princípios fundamentais da Passivhaus devem ser avaliados e aplicados com as adaptações cabíveis no seu emprego aos climas quentes, principalmente quanto ao desempenho dos materiais e sistemas utilizados, quanto também às técnicas passivas que possibilitem a otimização das soluções empregadas.

\section{PROJETO ARQUITETÔNICO}

O Instituto de Artes Lygia Pape se localizará na Rua Ruy Pinto Bandeira, no bairro Jardim Camburi, na cidade de Vitória-ES, seu terreno é limitado pela Avenida Munir Hilal e a Rua Alvin Borges da Silva. O instituto terá capacidade para atender até 80 alunos, em três turnos, totalizando 240 alunos, e necessitará de até 16 funcionários por turno para seu funcionamento.

O instituto levará o nome da artista plástica Lygia Pape, expoente do Construtivismo brasileiro, personagem fundamental na Vanguarda artística do país. Ao usar o nome da artista visa-se trazer ao conhecimento popular sua obra e sua importância para as Artes no Brasil.

O melhor formato estudado para o edifício é o retangular, essa geometria proporciona menores áreas de fachada nos eixos de maior insolação diurna - leste/oeste. No caso do hemisfério sul, a trajetória solar ocorre prioritariamente à norte, devido ao ângulo de inclinação do sol (Figura 6), portanto esta fachada irá receber radiação solar durante todo o dia, assim é fundamental, além de uma eficiente envoltória térmica, proteção das aberturas com sombreamento direto.

Figura 06 - Implantação do Inst. De Artes Lygia Pape.

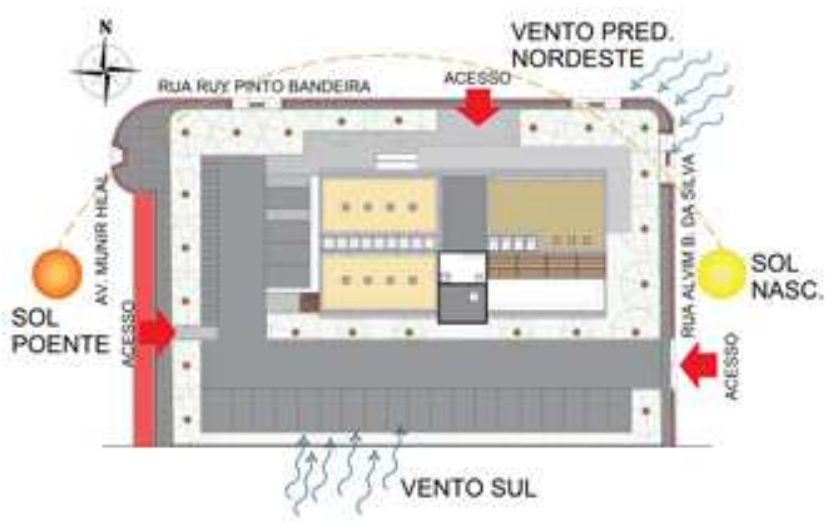

Fonte: Acervo pessoal.

Quanto à ventilação é importante posicionar as aberturas para que estas recebam os ventos predominantes no verão, e protegê-las contra os ventos frios no inverno. Uma das soluções que melhor atende à proteção das 
janelas são os brises. Portanto, nas fachadas Norte e Sul foram utilizados brises verticais móveis ao longo de todo primeiro pavimento, onde se encontram os ateliês, já no pavimento térreo, uma marquise protege as aberturas das fachadas Norte e Leste (Figuras 7 e 8).

Figura 07 - Vista frontal (Norte) do Inst. de Artes Lygia Pape.

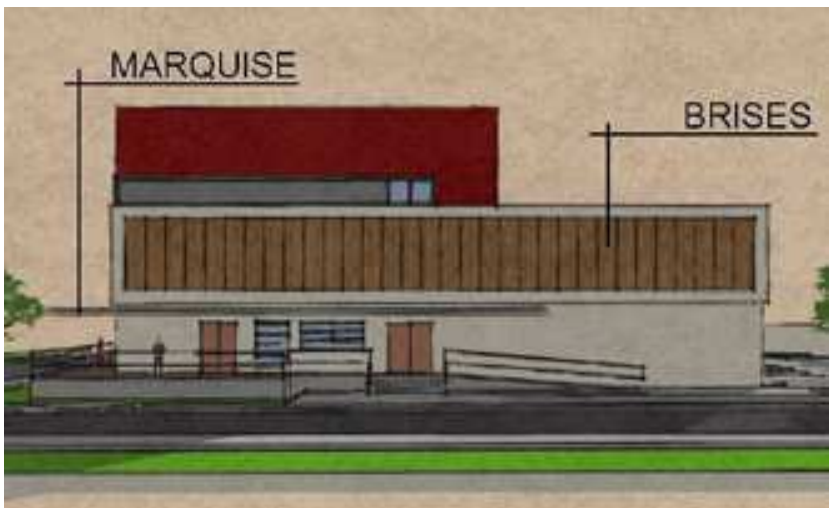

Fonte: Acervo pessoal.

Figura 08 - Perspectiva (vista sudeste) do Inst. de Artes Lygia Pape.

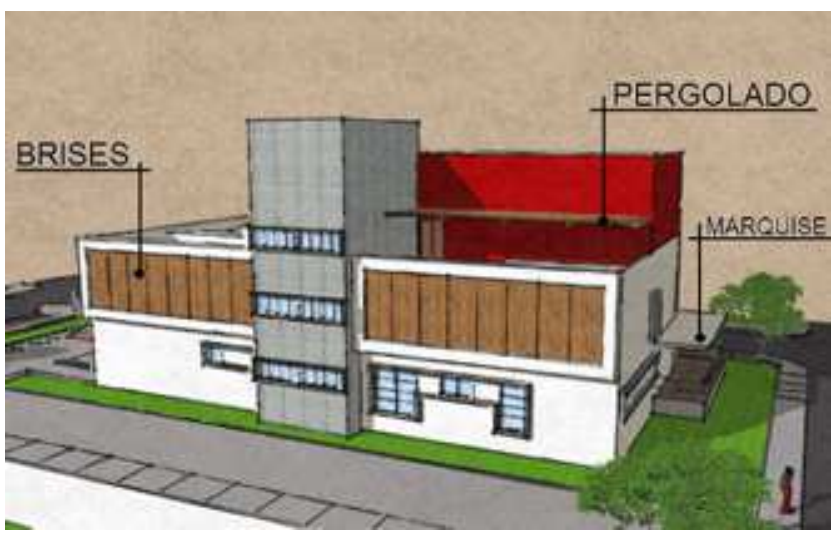

Além disso, o modelo geométrico compacto e retangular proposto é capaz de fornecer maiores opções de aberturas para iluminação natural, reduzindo o consumo energético no período diurno. A edificação ainda foi elevada, o que contribui para passagem de ventilação e ar fresco proveniente do solo, e toda arborização foi pensada para favorecer o microclima local e atuar no direcionamento e controle dos ventos junto à edificação.

O projeto arquitetônico do Instituto de Artes Lygia Pape abrange em seu pavimento térreo uma galeria de exposições com acesso independente da edificação principal, toda a parte administrativa (secretaria, escritório, almoxarifado e arquivo), as dependências de apoio aos funcionários (vestiários, copa e DML), uma livraria-café, também com acesso independente e deck coberto. Todo o bloco central do edifício recebe as escadas, os elevadores e os banheiros de apoio aos usuários (Figura 9).

Figura 09 - Planta baixa (térreo).

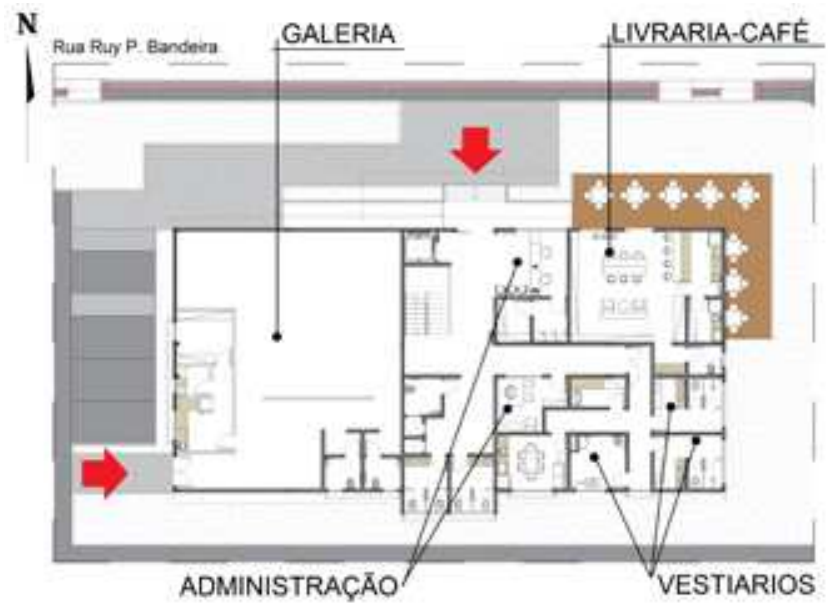

Fonte: Acervo pessoal.

Os vestiários foram posicionados a Leste, no setor de maior insolação, assim como as áreas de apoio da galeria a Oeste. O café localiza-se a Nordeste, sendo protegido pela marquise, e a Sul encontra-se a copa e os banheiros de apoio aos usuários com ampla ventilação.

O primeiro pavimento da edificação recebeu todos os ateliês e salas de estudo. À Norte encontra-se os ateliês de desenho, pintura, escultura e gravura, visto que, a umidade é um fator que pode comprometer os materiais utilizados na oficina. Já à Sul estão locadas a sala multimídia, o ateliê kids, de fotografia e cerâmica, que necessitam de maior resfriamento (Figura 10).

O segundo pavimento do instituto abriga o auditório, locado à Nordeste, e o terraço voltado para sudeste, sendo protegido também por um pergolado inclinado à Norte, 0 que favorece o sombreamento e a ventilação. Deste modo, o espaço recebe apenas a insolação da manhã sendo mais bem utilizado nos períodos da tarde e da noite (Figura 11).

Figura 10 - Planta baixa (1o pavimento).

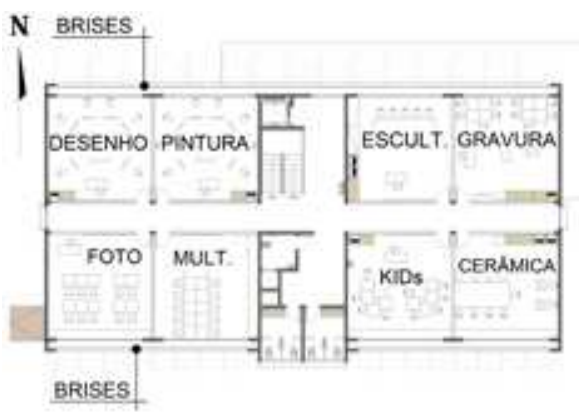

Fonte: Acervo pessoal. 
Figura 11 - Planta baixa (2o pavimento).

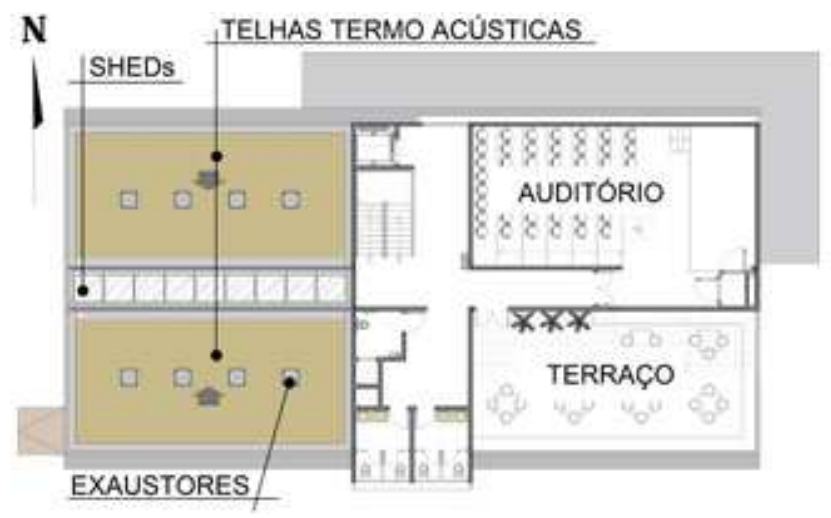

Fonte: Acervo pessoal.

A cobertura é composta por telhas termo acústica, em geral foram utilizadas platibandas em todo o telhado, ademais a face Oeste recebeu sobre a circulação do primeiro pavimento aberturas zenitais que permitem a captação da iluminação natural, em ângulos que não proporcionem incidência solar direta e nem entrada de chuvas (Figura 12).

Figura 12 - Planta baixa (Cobertura).

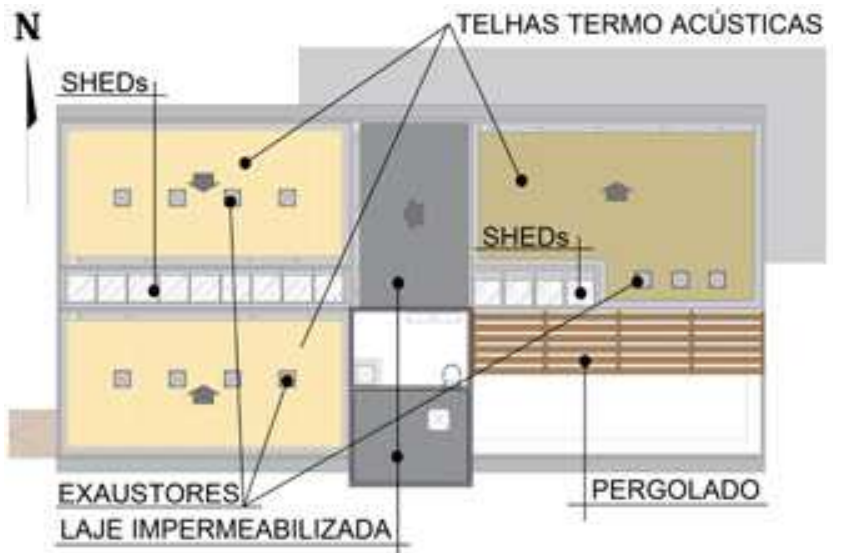

Fonte: Acervo pessoal.

\section{SOLUÇÕES TÉCNICAS E CONSTRUTIVAS}

Neste item são apresentadas as soluções aplicadas ao projeto de acordo com as técnicas estudadas e os princípios fundamentais do conceito Passivhaus.

\subsection{Paredes e envoltória externa}

Para o projeto proposto neste estudo, a melhor solução envolveu a aplicação do Poliestireno Expandido (EPS) com espessura de $40 \mathrm{~mm}$ nas paredes externas e $80 \mathrm{~mm}$ na cobertura da edificação, visto que esta recebe toda insolação direta. É importante salientar que as paredes internas não receberão o isolamento térmico, sendo necessário o uso do EPS apenas nas paredes externas junto a outros métodos de sombreamento e proteção solar.

\subsection{Cobertura}

A NBR 15220 (ABNT, 2005) recomenda, para a zona bioclimática 8 , o uso de telhas cerâmicas sem forro ou em materiais de transmitância térmica acima dos valores tabelados, pintadas em cores claras. Deste modo, são utilizadas na cobertura do Instituto de Artes, telhas termo acústicas na cor bege, também com isolamento em EPS incluso e com condutividade térmica de 0,245 W/m.k. Já as lajes de concreto nervurada recebem isolamento térmico em EPS, com espessura de $80 \mathrm{~mm}$.

Ainda de acordo com a NBR 15220 (ABNT, 2005) são necessárias áreas de ventilação entre as lajes e as coberturas. Visto que no projeto, tanto as telhas utilizadas quanto as lajes recebem isolamento térmico, não há necessidade de ventilação entre seus vãos. Entretanto para auxiliar na ventilação natural da edificação são empregados sheds com inclinação de $23 \%$, voltados para o sul, na cobertura da ala oeste do primeiro pavimento e no corredor de acesso ao terraço e ao auditório no segundo pavimento. Além disso, para complementar o sombreamento e proteção do deck e do acesso principal no térreo, é utilizada uma marquise de concreto que avança 3,00m sobre a parte frontal da edificação.

\subsection{Esquadrias}

Para o projeto do Instituto de Artes, todas as esquadrias são em Policloreto de vinila (PVC) e as esquadrias externas recebem vidros duplos com câmara de ar e alto fator de proteção solar. Para as maiores aberturas no primeiro pavimento, voltadas a norte e a sul, recebendo assim as maiores insolações durante todo o dia, são empregados brises verticais móveis em madeira plástica. Já para as básculas e janelas dos outros pavimentos, a proteção contra as intempéries é conferida por caixas em concreto de espessura $30 \mathrm{~cm}$, projetadas para fora das paredes externas. As portas externas também recebem isolamento térmico em EPS com 40mm de espessura.

\subsection{Pisos}

No projeto em estudo, a laje do térreo não recebe isolamento térmico, apenas acabamento em cimento queimado e é elevada $87 \mathrm{~cm}$ do solo, para proteger o edifício da umidade e garantir a troca de calor com o mesmo. Além disso, a elevação da laje do térreo permite a troca de calor com o ar externo em contato com o piso, assim com o isolamento térmico das lajes de cobertura, permite-se uma troca térmica vertical entre os pavimentos, 
já que o ar mais frio tende a descer, e o ar mais quente é retirado do ambiente por exaustores.

\subsection{Ventilação}

A ventilação híbrida é aplicada ao edifício através dutos de exaustão em todos os ambientes e nas circulações, onde não há emprego do sheds ou outro meio de retirada direta do calor. Além disso, no auditório, na galeria de exposições e no escritório, que não possuem aberturas externas, serão utilizados aparelhos de ar condicionado.

Os aparelhos de ar condicionado utilizados na galeria e no auditório serão do modelo split com grelha e dutos, deste modo, pode-se controlar a velocidade do ar dentro do ambiente, que segundo a norma Passivhaus não pode ultrapassar $0,1 \mathrm{~m} / \mathrm{s}$. Ainda, no escritório será utilizado um aparelho split comum, devido à pequena área do cômodo, permitindo-se nos períodos menos quentes a troca de ar com o ambiente por janelas internas que se abrem para a circulação.

\section{DESEMPENHO TÉRMICO DO EDIFÍCIO}

A ferramenta PHPP, utilizada para apreensão de dados quanto à eficácia de regulagem térmica da edificação e sua capacidade de renovação do ar interior, trata-se de um programa computacional em formato de planilha. Esse recurso foi desenvolvido pelo Instituto Passivhaus como modelo para verificação de requisitos e obtenção da certificação referente ao conceito. Neste artigo, os dados obtidos serão comparados aos quesitos de avaliação da norma Passivhaus e as exigências da NBR 15220 para a zona bioclimáticas 8, onde está inserido o município de Vitória - ES.

Para obtenção dos dados, a ferramenta de cálculo PHPP foi empregada em seu modelo de teste, portanto serão apenas apresentados os valores referentes às transmitâncias térmicas dos elementos externos e a taxa de renovação de ar da edificação em análise. O programa é composto por trinta e duas abas que verificam diversas variáveis do projeto, desde aspectos materiais, tipo de solo, quantidade de usuários e equipamentos utilizados.

Para o cálculo das transmitâncias térmicas (U) dos elementos foi necessário o preenchimento das informações exigidas pela planilha, tais como: os valores de condutividade térmica $(\lambda)$ de cada material, os valores de resistência superficial interna (Rsi) e externa (Rse) e a espessura dos componentes utilizados. A Tabela 1 demonstra os resultados obtidos para as paredes externas.

Observando os dados apresentados na Tabela 1, verifica-se o valor de transmitância térmica de todas as paredes externas da edificação em estudo, 0,742 W/ $\mathrm{m}^{2} \mathrm{~K}$, bem como sua espessura, $220 \mathrm{~mm}$. Deste modo, constata-se que emprego do EPS junto ao bloco cerâmico é capaz de reduzir consideravelmente a apreensão de calor pelos elementos verticais do edifício. Além disso, a ferramenta PHPP facilita o cálculo, exigindo apenas informações de simples captação.

Tabela 01: Transmitância Térmica do edifício

\begin{tabular}{|c|c|c|c|c|}
\hline \multirow{4}{*}{$\begin{array}{c}\text { Transmitância térmica (U) } \\
\text { Externa }\end{array}$} & Rsi & 0,13 & Rse & 0,04 \\
\cline { 2 - 5 } & $\lambda(\mathrm{W} / \mathrm{mK})$ & \multicolumn{2}{|c|}{ Espessura (mm) } \\
\hline Reboco int. & 0,150 & \multicolumn{2}{|c|}{45} \\
\hline \multirow{2}{*}{ Reboco ext. } & 0,150 & \multicolumn{2}{|c|}{45} \\
\hline EPS & 0,040 & \multicolumn{2}{|c|}{40} \\
\hline Tijolo cer. & 0,900 & \multicolumn{2}{|c|}{90} \\
\hline U (W/m2k) & 0,742 & \multicolumn{2}{|c|}{ Total } & 220 \\
\hline
\end{tabular}

Fonte: MORISHITA, 2011; ABNT, 2005.

\section{RESULTADOS}

O conceito Passivhaus tem como regra básica o implemento de isolamento térmico em toda a envoltória da edificação. Para o projeto do Instituto de Artes, como já visto, foi empregado o EPS com $40 \mathrm{~mm}$, nas paredes externas, e $80 \mathrm{~mm}$, nas lajes de cobertura. A Tabela 2 apresenta os resultados dos valores de transmitância térmica (U), obtidos pela PHPP.

O valor de transmitância térmica das paredes externas é de $0,74 \mathrm{w} / \mathrm{m}^{2} \mathrm{k}$, ou seja, abaixo do valor recomendado pela NBR 15220 (ABNT, 2005), que é 3,6 w/ $\mathrm{m}^{2} \mathrm{k}$, assim como os pilares externos, com $0,78 \mathrm{w} / \mathrm{m}^{2} \mathrm{k}$ e as vigas com $0,75 \mathrm{w} / \mathrm{m}^{2} \mathrm{k}$ de transmitância. Do mesmo modo, a cobertura, a laje do terraço e a laje impermeabilizada atingiram valores bem menores que os exigidos pela mesma norma, $0,42,0,43$ e $0,44 \mathrm{w} / \mathrm{m}^{2} \mathrm{k}$ respectivamente, contra $2,3 \mathrm{w} / \mathrm{m}^{2} \mathrm{k}$ recomendada pela NBR 15220 (ABNT, 2005) para a zona bioclimática 8 .

O sistema de ventilação aplicado ao projeto privilegia a ventilação natural através de grandes aberturas, além disso, o formato compacto e horizontal da edificação permite melhor distribuição e renovação do ar interno 
na edificação. Assim, a taxa de renovação de ar, obtida através da PHPP, é de 0,57 renovações de ar por hora/dia, que se insere dentro da meta estabelecida pela norma Passivhaus, onde o valor máximo permitido é de 0,6 renovações de ar por hora/dia.

Tabela 02: Valores de transmitância térmica do Inst. de Artes.

\begin{tabular}{|c|c|c|}
\hline \multicolumn{3}{|c|}{ Transmitância térmica (U) } \\
\hline Descrição & Espessura & $U[\mathrm{w} / \mathrm{m} 2 \mathrm{k}]$ \\
\hline Parede ext. & $22 \mathrm{~cm}$ & 0,74 \\
\hline Pilares & $22 \mathrm{~cm}$ & 0,78 \\
\hline Vigas & $19 \mathrm{~cm}$ & 0,75 \\
\hline Cobertura & $33 \mathrm{~cm}$ & 0,42 \\
\hline & & \\
Laje do Terraço & $33 \mathrm{~cm}$ & 2,13 \\
\hline & & 0,44 \\
\hline Laje imp. & $18 \mathrm{~cm}$ & \\
\hline
\end{tabular}

Fonte: Acervo pessoal.

A taxa de renovação de ar é uma exigência importante quanto à higienização dos ambientes internos e proteção dos usuários contra doenças provenientes de alta permanência em ambientes fechados. As normas brasileiras, como já visto, estipulam áreas mínimas de abertura para iluminação e ventilação, entretanto não exigem a renovação de ar constante dentro da edificação.

\section{CONCLUSÕES}

O conceito Passivhaus baseado na norma europeia EN ISO 137790, exige excelência no conforto térmico do usuário, inclusive limitando as temperaturas internas da edificação tanto no verão, quanto no inverno. Através das comparações realizadas nesta pesquisa, entre o modelo Passivhaus e as normas brasileiras, percebe-se que quanto aos requisitos de eficiência energética, as normas e certificações nacionais focam no consumo de energia primária. No entanto, no que diz respeito ao desempenho térmico das edificações, estas normas não apresentam soluções explícitas e direcionadas. Logo, a aplicação dos princípios fundamentais do conceito Passivhaus em edificações brasileiras indica uma redução do gasto energético durante a fase de uso e manutenção da edificação.

A partir da Arquitetura Passiva, o conceito Passivhaus agrega métodos simples para a otimização do conforto térmico dentro de uma edificação. Deste modo, os cinco princípios fundamentais estabelecidos pela mesma são passíveis de adaptação e aplicação em diversos contextos. O isolamento térmico do edifício abre espaço para o uso de qualquer material com baixa transmitância térmica, podendo ser aplicada a qualquer edificação de qualquer perfil ou tamanho. Observa-se assim, a viabilidade de aplicação da norma alemã, com adequações as peculiaridades climáticas, a edificações localizadas na zona bioclimática brasileira 8 .

Outro ponto fundamental no controle das temperaturas internas para a Passivhaus são as esquadrias. Sua correta locação de acordo com a insolação, ventos predominantes e demais condicionantes do sítio, auxilia na melhora da temperatura interna e na economia de energia elétrica, uma vez que o emprego da ventilação natural proporciona melhor conforto térmico reduzindo o consumo de energia.

A metodologia Passivhaus envolve técnicas claras e diretas, ou seja, seus cinco princípios fundamentais, e, além disso, requisitos precisos de controle da temperatura, de renovação e velocidade do ar dentro da edificação. Esses parâmetros podem ser medidos e quantificados com precisão pela ferramenta PHPP, diferentemente das demais certificações, em que os métodos avaliativos englobam, na maioria das vezes, análise de projeto, documentação e especificação de materiais.

\section{REFERÊNCIAS}

ABNT - ASSOCIAÇÃO BRASILEIRA DE NORMAS TÉCNICAS. NBR 15220-3: Desempenho térmico de edificações - Parte 3: Zoneamento bioclimático brasileiro e estratégias de condicionamento térmico passivo para habitações de interesse social. Rio de Janeiro, 2005.

NBR 15575: Edificações habitacionais Desempenho. Parte 1: Requisitos Gerais - SVVIE. Rio de Janeiro: ABNT, 2013

COSTA, Sara Luísa P. G. da. Eficiência energética de edifícios: Conceito Passivhaus. Dissertação de mestrado, Engenharia do Ambiente, Instituto Superior de Agronomia da Universidade de Lisboa. 2015.

CUNHA, Eduardo Grala da. Elementos de Arquitetura de Climatização Natural: Método projetual buscando a eficiência energética nas edificações. Porto Alegre: Masquatro Editora, 2006. 
DALBEN, Renata. FREITAS, Juliana M. R. de. CUNHA, Eduardo Grala da. Conceito Passivhaus aplicado ao clima brasileiro. Revista da Arquitetura IMED. Janeiro a julho de 2015. Universidade Federal de Pelotas. Rio Grande do Sul.

FROTA, Anésia Barros. SCHIFFER. Sueli Ramos. Manual do Conforto Térmico: arquitetura e urbanismo. São Paulo: Studio Nobel, 2003.

FROTA, Anésia Barros. Geometria da Insolação / Anésia Barros Frota. São Paulo: Geros, 2004.

GAVIÃO, João Rui S. P. Princípios para a aplicação do conceito Passive House em Portugal. Dissertação de mestrado em Construção e Reabilitação Sustentáveis. Universidade do Minho, Escola de Engenharia. Novembro de 2012.

GURGEL, Mirian. Design Passivo - baixo consumo energético: guia para conhecer, entender, e aplicar os princípios do design passivo em residenciais / Mirian Gurgel. São Paulo: Editora Senac São Paulo, 2012.

LAMBERTS, R.; DUTRA, L.; PEREIRA, F. O. R. Eficiência energética na arquitetura. $2^{a}$ Edição, revisada. São Paulo: PW, 2014.

MORISHITA, Claudia et al. Catálogo de propriedades térmicas de paredes e coberturas. Laboratório de Eficiência Energética em Edificações. Florianópolis, 2011.

WASSOUF, Micheel. Da casa passiva à norma Passivhaus: A Arquitetura Passiva em climas quentes. Barcelona: Anman Gràfiques del Vallès, 2014. 